\title{
Environmental factors influencing the variability of Lingulodinium polyedrum and Scrippsiella trochoidea (Dinophyceae) cyst production
}

\section{Factores ambientales que influyen en la variabilidad de la producción de quistes de Lingulodinium polyedrum y Scrippsiella trochoidea (Dinophyceae)}

\author{
JL Peña-Manjarrez*1,2, G Gaxiola-Castro² ${ }^{2}$ J Helenes-Escamilla ${ }^{3}$ \\ ${ }^{1}$ Dirección General de Educación en Ciencia y Tecnología del Mar, Centro de Estudios Tecnológicos del Mar en Ensenada, \\ Km 6.5 Carretera Ensenada-Tijuana, Ensenada, Baja California, México. \\ ${ }^{2}$ Departamento de Oceanografía Biológica, División de Oceanología, Centro de Investigación Científica y de Educación \\ Superior de Ensenada (CICESE), Km 107 Carretera Tijuana-Ensenada, Ensenada, Baja California, México. \\ *E-mail: jopema@cicese.mx \\ ${ }^{3}$ Departamento de Geología, División de Ciencias de la Tierra, Centro de Investigación Científica y de Educación Superior de \\ Ensenada (CICESE), Km 107 Carretera Tijuana-Ensenada, Ensenada, Baja California, México.
}

\begin{abstract}
This study analyzes the temporal variability of the abundance of Lingulodinium polyedrum and Scrippsiella trochoidea resting cysts in surface sediments, as well as the temporary cysts and vegetative cells of L. polyedrum in the upper water column of Todos Santos Bay (Baja California, Mexico). Samples were collected monthly from January 2002 to June 2005 at four sites. Multidimensional scaling analysis and analysis of similarities revealed that resting cysts are distributed heterogeneously according to the sedimentary environment. Surface water temperature, inorganic dissolved phosphate, and the abundance of temporary cysts were the main factors influencing the abundance of $L$. polyedrum resting cysts, while the variability of temporary cysts was explained by the abundance of planktonic cells. Scrippsiella trochoidea resting cysts showed no statistical relationship with the environmental factors considered. Local runoff during the rainy season and sewage from the city of Ensenada contribute to the eutrophication of the bay. This is an important factor for future blooms since inorganic dissolved nitrate + nitrite and daylight hours during the spring-summer season are not limiting factors for dinoflagellate growth. After the dinoflagellate blooms, there was massive cyst production of both species, and the new cysts settled on the surface sediments. Surface water temperatures between $17^{\circ} \mathrm{C}$ and $22.5^{\circ} \mathrm{C}$ during spring-summer appear to trigger excystment in these species.
\end{abstract}

Key words: Baja California, cysts, dinoflagellates, Lingulodinium, Scrippsiella.

\section{Resumen}

Se estudió la variabilidad temporal de las abundancias de quistes de reposo de Lingulodinium polyedrum y Scrippsiella trochoidea en los sedimentos superficiales, así como los quistes temporales y células vegetativas de L. polyedrum en la parte superior de la columna de agua en la Bahía de Todos Santos (Baja California, México). Las muestras fueron recolectadas mensualmente de enero de 2002 a junio de 2005 en cuatro localidades. El análisis multidimensional escalado y el análisis de similitud mostraron que los quistes de reposo se distribuyen heterogéneamente de acuerdo con el ambiente sedimentario. Los principales factores que influyeron en la producción de quistes de reposo para L. polyedrum son la temperatura superficial, los fosfatos inorgánicos y la abundancia de quistes temporales, mientras que la variabilidad de los quistes temporales se explicó por la abundancia de células planctónicas. Los quistes de reposo de S. trochoidea no tuvieron relación estadística con los factores ambientales considerados. Las escorrentías locales durante la temporada de lluvias y las aguas residuales de la ciudad de Ensenada contribuyen a la eutroficación de la bahía, lo cual es un factor importante para futuros florecimientos donde los nitratos + nitritos inorgánicos disueltos y las horas de luz durante primavera-verano no son limitantes para el crecimiento de los dinoflagelados. Al término de los florecimientos de dinoflagelados hubo una producción masiva de quistes de ambas especies, en los que los quistes recién formados se depositaron en los sedimentos superficiales. El factor que induce el desenquistamiento parece ser una ventana térmica entre $17^{\circ} \mathrm{C}$ y $22.5^{\circ} \mathrm{C}$ de la columna de agua durante primavera-verano.

Palabras clave: Baja Calirfornia, dinoflagelados, quistes, Lingulodinium, Scrippsiella.

\section{Introduction}

Several dinoflagellate species produce cysts as part of their life cycle. Cysts play an important role in the ecology and bloom dynamics of dinoflagellate species: genetic

\section{Introducción}

Varias especies de dinoflagelados producen quistes como parte de su ciclo de vida. Los quistes desempeñan varios papeles importantes en la ecología y dinámica de los florecimientos 
recombination (Dale 1983), dispersal (Anderson et al. 2003), survival under unfavourable conditions (Nehring 1993), termination of blooms (Heiskanen 1993), seeding for initiation of future blooms, and regulation of seasonal succession (Anderson et al. 1983, Cembella et al. 1988, Ishikawa and Taniguchi 1996). Therefore, information on the distribution and abundance of cysts in sediments and the water column is helpful for understanding the ecology and bloom dynamics of many dinoflagellate species.

Radi and DeVernal (2004) suggested that dinoflagellate cyst assemblages can be used to reconstruct primary productivity, temperature, and salinity, and showed that the most important environmental parameters related to dinocyst distribution in the restricted embayment near Vancouver Island are distance to the shore, distance to the harbor, spring sea surface salinity, spring phosphate concentration, and spring productivity. Holzwarth et al. (2007) studied the distribution of organicwalled dinoflagellate cysts in shelf surface sediments of the Benguela upwelling system in relation to environmental conditions and reported that in addition to longitudinal gradients the dinocyst distribution clearly reflects regional environmental features.

Even though the environmental factors that control encystment and excystment of dinoflagellates are not totally understood, some laboratory experiments suggest that phosphorous and/or nitrogen limitation enhance the onset of sexual reproduction and promote encystment in some species of dinoflagellates (Figueroa and Bravo 2005). However, there is no evidence that in natural conditions this limitation has the same effect (Godhe et al. 2001).

Off southern California, Prauss (2002) documented the influence of recent global warming on marine dinoflagellate cysts from the central Santa Barbara Basin. Other studies explored the changes in cyst abundance, the composition of cyst assemblages, and their diversity, and concluded that these changes reflect major shifts in climate and ocean circulation in the region over the last 40,000 years (Pospelova et al. 2006, 2008). It has also been found that the increase in red tides and other harmful algal blooms during the past 50 years on both the Atlantic and Pacific coasts of Canada seems to be driven by global-scale factors, such as climate change and increased international shipping trade (Mudie et al. 2002). However, only scant information is available for the spatial and temporal distribution of recent cysts and the palynological record from Mexico's shoreline (Martínez-Hernández and HernándezCampos 1991, Peña-Manjarrez et al. 2005, Martínez-López et al. 2007, Vásquez-Bedoya et al. 2008).

The Southern California Bight has seen recurrent dinoflagellate blooms since at least 1901 (Holmes et al. 1967). The causative species have been Lingulodinium polyedrum (Stein) Dodge, Prorocentrum micans (Ehrenberg), Prorocentrum gracile (Schütt), Ceratium furca (Ehrenberg) Claparède and Lachmann, and Scrippsiella trochoidea (Stein) Loeblich III (Gregorio and Pieper 2000, Peña-Manjarrez et al. 2001). Two of these species produce resting cysts: $L$. polyedrum produces de dinoflagelados: recombinación genética (Dale 1983), dispersión (Anderson et al. 2003), supervivencia en condiciones desfavorables (Nehring 1993), terminación de los florecimientos (Heiskanen 1993), semilla para el inicio de futuros florecimientos y regulación de la sucesión estacional (Anderson et al. 1983, Ishikawa y Taniguchi 1996). Por lo tanto, la información sobre la distribución y abundancia de quistes en los sedimentos y en la columna de agua es esencial para conocer la ecología y la dinámica de los florecimientos de muchas especies de dinoflagelados.

Radi y DeVernal (2004) sugirieron que los conjuntos de quistes de dinoflagelados pueden utilizarse para deducir las condiciones de la producción primaria, la temperatura y la salinidad, y demostraron que los parámetros ambientales más importantes que se relacionan con la distribución de dinoquistes cerca de la isla de Vancouver son la distancia a la costa, la distancia al puerto, los valores de salinidad superficial en primavera, la concentración de fosfatos y la productividad de primavera. Holzwarth et al. (2007) estudiaron la distribución de quistes de dinoflagelados con paredes orgánicas, en los sedimentos superficiales de la plataforma del sistema de surgencias de Benguela en relación con las condiciones ambientales y reportaron que, además de los gradientes longitudinales, la distribución de dinoquistes reflejaba claramente las características ambientales.

Si bien los factores ambientales que controlan el enquistamiento y exquistameinto de dinoflagelados no se han entendido totalmente, algunos experimentos de laboratorio sugieren que el fósforo y/o la limitación de nitrógeno inducen la reproducción sexual y promueven el enquistamiento en algunas de estas especies (Figueroa y Bravo 2005). Sin embargo, no hay evidencias de que en condiciones naturales esta limitación produzca el mismo efecto (Godhe et al. 2001).

Varios estudios han documentado la influencia del calentamiento global reciente sobre los quistes de dinoflagelados de la Cuenca de Santa Barbara (Prauss 2002). Otros trabajos han explorado la variabilidad en la abundancia de quistes, su composición y su diversidad, y han concluido que estas diferencias muestran los grandes cambios en el clima y la circulación oceánica en la región durante los últimos 40,000 años (Pospelova et al. 2006, 2008). También se ha encontrado que los incrementos en los florecimientos algales nocivos durante los últimos 50 años en las costas del Atlántico y el Pacífico de Canadá parecen estar controlados por factores de escala global como el cambio climático y el incremento en el tráfico de embarcaciones comerciales (Mudie et al. 2002). Sin embargo, son escasos los estudios sobre la distribución espacial y temporal de quistes recientes, así como el registro palinológico de las costas de México (Martínez-Hernández y Hernández-Campos 1991, Peña-Manjarrez et al. 2005, Martínez-López et al. 2007, Vásquez-Bedoya et al. 2008).

La zona costera del Sur de California ha presentado florecimientos recurrentes de dinoflagelados al menos desde 1901 (Holmes et al. 1967). Las especies más reportadas durante estos florecimientos son Lingulodinium polyedrum (Stein) 
a dinosporine-walled cyst, while $S$. trochoidea produces a calcareous one.

The ecology of encystment and excystment of $L$. polyedrum and S. trochoidea in Todos Santos Bay is a complex process that involves many unknown mechanisms. Furthermore, the ecological responses to the environmental conditions that trigger stage transitions of these species in the bay are still marginal. This study relates some environmental factors, such as the availability of inorganic dissolved nutrients, photosynthetically active irradiance, surface water temperature, and salinity, to the variability of dinoflagellate cysts and vegetative cells.

\section{Materials and methods}

\section{Study area}

Todos Santos Bay (TSB) is located on the northwestern Pacific coast of Baja California, Mexico $\left(31^{\circ} 42^{\prime}-31^{\circ} 55^{\prime} \mathrm{N}\right.$, $116^{\circ} 36^{\prime}-116^{\circ} 48^{\prime} \mathrm{W}$; fig. 1). The bay has a surface area of approximately $250 \mathrm{~km}^{2}$ and a mean depth of $50 \mathrm{~m}$. A canyon slightly deeper than $300 \mathrm{~m}$ is found in its southwestern part. The city of Ensenada $\left(228 \mathrm{~km}^{2}\right.$, approximately 300,000 inhabitants) is located to the east of the bay. Upwelling processes in shore areas close to the bay introduce cold and

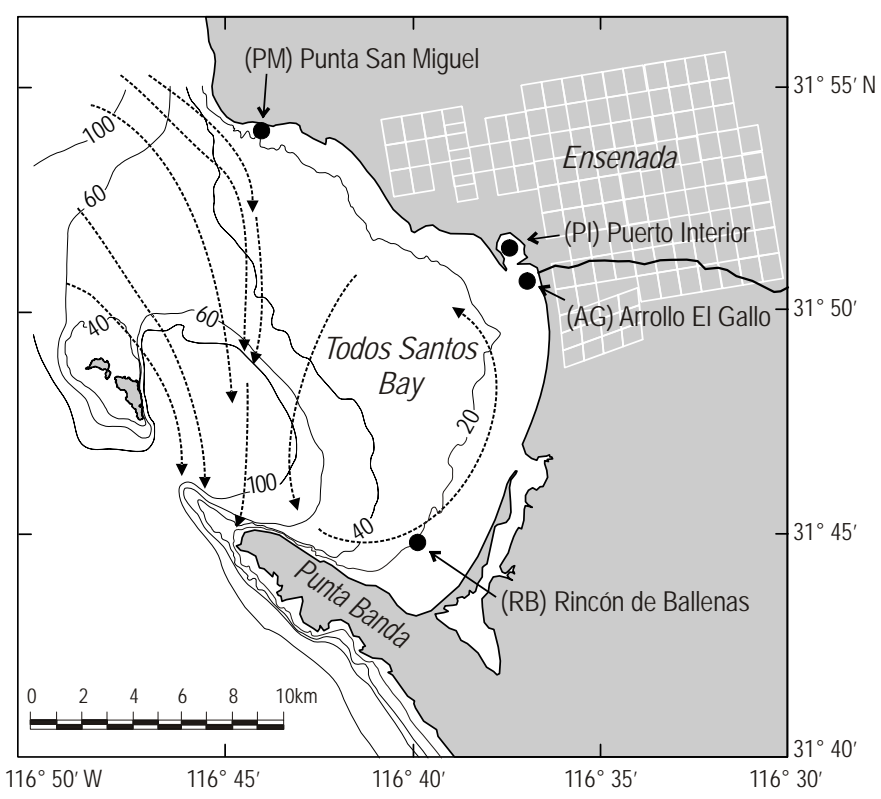

Figure 1 Location of Todos Santos Bay (Pacific coast of Baja California, Mexico). The bathymetry (in meters) is indicated by continuous lines. Dotted arrows show the main surface water circulation inside the bay during the spring-summer season. Black circles indicate the sampling sites visited monthly from January 2002 to June 2005.

Figura 1 Ubicación de la Bahía de Todos Santos. La batimetría (en metros) se indica con líneas continuas. Las flechas punteadas muestran la circulación superficial dominante en el interior de la bahía durante primavera-verano. Los círculos negros indican los sitios de monitoreo mensual en el periodo enero de 2002 a junio de 2005.
Dodge, Prorocentrum micans (Ehrenberg), Prorocentrum gracile (Schütt), Ceratium furca (Ehrenberg) Claparède y Lachmann, y Scrippsiella trochoidea (Stein) Loeblich III (Gregorio y Pieper 2000, Peña-Manjarrez et al. 2001). Lingulodinium polyedrum produce quistes con paredes de dinosporina, mientras que $S$. trochoidea produce quistes calcáreos.

La ecología del enquistamiento y exquistamiento de $L$. polyedrum y S. trochoidea en la Bahía de Todos Santos es un proceso complejo que involucra muchos mecanismos desconocidos. Además, las respuestas ecológicas a las condiciones ambientales que desencadenan la fase de transición de estas especies en la bahía son todavía poco conocidas. Por lo anterior, el objetivo de este trabajo fue relacionar factores ambientales como la disponibilidad de nutrientes inorgánicos disueltos, la irradiancia fotosintéticamente activa, la temperatura superficial y la salinidad, con la variabilidad de los quistes y las células vegetativas de dinoflagelados.

\section{Materiales y métodos}

\section{Área de estudio}

La Bahía de Todos Santos (BTS) se localiza en la costa noroeste del Pacífico de Baja California, México $\left(31^{\circ} 42^{\prime}-31^{\circ} 55^{\prime} \mathrm{N}, 116^{\circ} 36^{\prime}-116^{\circ} 48^{\prime} \mathrm{W}\right.$; fig. 1), y tiene una superficie aproximada de $250 \mathrm{~km}^{2}$ y una profundidad media de $50 \mathrm{~m}$. En el suroeste de la bahía se ubica un cañón con profundidad ligeramente mayor a $300 \mathrm{~m}$. La ciudad de Ensenada (228 $\mathrm{km}^{2}$, con aproximadamente 300,000 habitantes) está situada al este de la bahía. Los procesos de surgencia en las áreas costeras cercanas a la bahía introducen agua subsuperficial fría y rica en nutrientes, lo que resulta en una disminución de la temperatura superficial en la BTS (Torres et al. 2006).

Durante el periodo otoño-invierno las corrientes superficiales transcurren a un promedio de $5 \mathrm{~cm} \mathrm{~s}^{-1}$ (Álvarez-Sánchez et al. 1988). Este patrón de circulación promueve un flujo principalmente en dirección sureste hacia dentro de la bahía, excepto cuando el flujo cambia de dirección hacia el noreste al llegar a Punta Banda. Este cambio en la dirección promueve una celda de circulación contra solem que induce un flujo superficial hacia fuera de la bahía por el área de Punta Banda (fig. 1).

Aunque la región del sur de California está expuesta a sequías prolongadas, hay una breve temporada de lluvias de invierno caracterizada por oscilaciones multidecadales $(\sim 40$ años), decadales ( $\sim 15$ años) e interanuales de la precipitación, que se asocian con las señales del Índice de Oscilación del Sur y la Oscilación Decadal del Pacífico (Reyes-Coca y TroncosoGaytán 2004).

\section{Muestreo y análisis de laboratorio}

Se recolectaron mensualmente sedimentos superficiales desde enero de 2002 hasta junio de 2005 en cuatro localidades dentro de la BTS: San Miguel (SM), Puerto Interior (PI), Arroyo el Gallo (AG) y Rincón Ballenas (RB) (fig. 1). Las muestras se recolectaron con una draga Birgé-Ekman 
nutrient-rich subsurface water, resulting in a lower sea surface temperature in TSB (Torres et al. 2006).

During the fall-winter period, surface currents average $5 \mathrm{~cm} \mathrm{~s}^{-1}$ (Álvarez-Sánchez et al. 1988). The circulation pattern promotes a mainly southeastern flux into the bay, except where the flux changes direction to the northeast on reaching Punta Banda. This change in direction promotes a contra solem cell circulation that induces surface water to flow out of the bay through the Punta Banda area (fig. 1).

Although the southern California region is prone to prolonged droughts, there is a short winter rainy season characterized by multidecadal ( $\sim 40$ years), decadal ( $\sim 15$ years), and interannual oscillations of precipitation, which are associated with signals from the Southern Oscillation Index and Pacific Decadal Oscillation (Reyes-Coca and Troncoso-Gaytán 2004).

\section{Sampling and laboratory analysis}

Surface sediments were collected monthly from January 2002 to June 2005 at four sampling stations within TSB: San Miguel (SM), Puerto Interior (PI), Arroyo El Gallo (AG), and Rincón Ballenas (RB) (fig. 1). Samples were collected using a modified Birge-Ekman style box sediment sampler. The first $2 \mathrm{~cm}$ of the sediments were sampled and stored in plastic bags at $4^{\circ} \mathrm{C}$ until analysis. Samples were then sieved through 147and $15-\mu \mathrm{m}$ meshes. The resulting fraction underwent density separation during $15 \mathrm{~min}$ at $2250 \mathrm{~g}$ in a sodium polytungstate $\left(\mathrm{Na}_{6}\left[\mathrm{H}_{2} \mathrm{~W}_{12} \mathrm{O}_{40}\right]\right)$ solution with specific gravity $=2.0 \mathrm{~g} \mathrm{~cm}^{-3}$. The remaining material was mounted on permanent slides with glycerine jelly and sealed with optic resin (NOA-61/Y37-322). Slides were surveyed using a light microscope (Carl Zeiss AxioscoP40) under $400 \times$ magnification, and the total cysts of L. polyedrum and S. trochoidea were counted in each sample. Since extant controls were not used, relative abundances were calculated as the total of cysts per gram of dry weight sediment.

Continuous temperature and salinity profiles from the water column were obtained with a CTD (SBE19-03, Seabird Electronics). Seawater samples for the analysis of dissolved inorganic nutrients and dinoflagellate cells were collected using a segmented pipe (0-3 m depth). A segmented flux autoanalyzer (Skalar SANplus System II) was used to determine the concentration $(\mu \mathrm{M})$ of dissolved inorganic nitrate + nitrite and dissolved inorganic phosphate. As a measure of the eutrophication level, we estimated a nutrient eutrophication index by applying the method proposed by Karydis et al. (1983).

Phytoplankton samples were fixed with a concentrated lugol-acetate solution. Quantification of dinoflagellate cells and temporary cysts was performed following the Utermöhl (1958) technique using an inverted microscope with phase contrast at 200× magnification (Olympus CK 2).

\section{Statistical analysis}

Multidimensional scaling analysis (MDS, Primer v.5) was performed to interpret the distribution pattern of resting cysts. modificada. Se recolectaron los primeros $2 \mathrm{~cm}$ de sedimentos y se mantuvieron en bolsas de plástico a $4^{\circ} \mathrm{C}$ hasta su análisis. Las muestras fueron tamizadas con mallas de 147 y $15 \mu \mathrm{m}$. La fracción resultante se separó por gradiente de densidad durante $15 \mathrm{~min}$ a $2250 \mathrm{~g}$ en una solución de politungstato de sodio $\left(\mathrm{Na}_{6}\right.$ $\left.\left[\mathrm{H}_{2} \mathrm{~W}_{12} \mathrm{O}_{40}\right]\right)$ con densidad específica $=2.0 \mathrm{~g} \mathrm{~cm}^{-3}$. El material recuperado se montó en preparaciones permanentes con gelatina glicerinada y sellado con resina óptica (NOA-61/Y37322). Las preparaciones se analizaron en un microscopio de luz (Carl Zeiss AxioscoP40) con magnificación de 400×. Los quistes de L. polyedrum y $S$. trochoidea fueron contados en su totalidad en cada muestra. Debido a que no se utilizó una muestra externa como control; se estimaron las abundancias relativas como el total de quistes por gramo de sedimento en peso seco.

Se obtuvieron perfiles continuos de temperatura y salinidad de la columna de agua con un CTD (SBE19-03, Seabird Electronics). Las muestras para el análisis de nutrientes inorgánicos disueltos y células de dinoflagelados se recolectaron con un tubo segmentado ( 0 a $3 \mathrm{~m}$ de profundidad). Las concentraciones $(\mu \mathrm{M})$ de nitratos + nitritos inorgánicos disueltos y fosfato inorgánico disuelto se determinaron con un autoanalizador de flujo segmentado (Skalar SANplus System II). Como medida del nivel de eutroficación, se estimó un índice de eutroficación por nutrientes aplicando el método propuesto por Karydis et al. (1983).

Las muestras de fitoplancton se fijaron con una solución concentrada de lugol-acetato. La cuantificación de las células de dinoflagelados y quistes temporales se realizó por el método de Utermöhl (1958) utilizando un microscopio invertido con contraste de fases (Olympus CK 2) y magnificación de 200×.

\section{Análisis estadístico}

Para interpretar el patrón de distribución de quistes de reposo se realizó un análisis multidimensional escalado (MDS, Primer v.5). Las matríces triangulares de similitud se construyeron utilizando la transformación $\log 10(x+1)$ de Bray-Curtis sobre las abundancias de quistes de reposo. Como datos de entrada para el análisis se utilizaron las abundancias de quistes de reposo de ambas especies. Los factores considerados como parámetros pasivos fueron la localidad, estación del año, y el tamaño del sedimento. Después del análisis MDE se realizó un análisis de similitud de dos vías sin réplica (ANOSIM) para probar la significancia de las diferencias entre localidades, utilizando la prueba de permutación sobre la matriz de similitud (Clarke y Green 1988). Para conocer el efecto de las factores ambientales sobre la variabilidad en la abundancia de quistes de reposo se realizó un análisis de regresión múltiple (ARM, Statistica v.7).

\section{Resultados}

\section{Temperatura}

Durante todo el periodo la temperatura superficial media en todas las localidades varió entre $12.7^{\circ} \mathrm{C}$ y $22.8^{\circ} \mathrm{C}$ (fig. 2a). Los 
Ranked lower triangular similarity matrices were constructed using the Bray-Curtis similarity measure on $\log (x+1)$ transformed resting cyst abundances. Dinoflagellate resting cyst abundances for both species were used as input data. Factors considered as passive parameters were location, season of the year, and sediment size. The MDS analysis was followed by a two-way crossed analysis of similarities with no replication (ANOSIM) to test the significance of differences among locations, using the permutation test on a similarity matrix (Clarke and Green 1988). Multiple regression analysis (MRA, Statistica v.7) was used to test the effect of environmental factors on the variability in the abundance of resting cysts.

\section{Results}

\section{Temperature}

Throughout the study period, average surface water temperature at all sampling locations ranged from $12.7^{\circ} \mathrm{C}$ to $22.8^{\circ} \mathrm{C}$ (fig. 2a). Lower values $\left(12^{\circ} \mathrm{C}\right.$ at $\mathrm{SM}$ and $14^{\circ} \mathrm{C}$ at $\left.\mathrm{RB}\right)$ were registered in winter when vertical mixing promoted a homogeneous temperature from surface to $20 \mathrm{~m}$ depth. Higher surface temperature values $\left(22^{\circ} \mathrm{C}\right.$ at $\mathrm{SM}$ and $24.5^{\circ} \mathrm{C}$ at $\left.\mathrm{RB}\right)$ were recorded during summer periods, when the water column was stratified. The winter-summer surface water temperature at TSB showed a difference of $8^{\circ} \mathrm{C}$ to $8.5^{\circ} \mathrm{C}$.

The CTD profiles (data not shown) indicated that TSB was thermally stratified during spring and summer. This stratification was highly variable between sampling sites: SM showed a well-mixed water column during most part of the year, whereas $\mathrm{RB}$, PI, and AG showed a stratified water column throughout the spring-summer season. Maximum variability in surface temperature was measured at SM and PI with an annual gradient of $9^{\circ} \mathrm{C}$, followed by RB with an annual gradient of $8^{\circ} \mathrm{C}$, and the minimum annual variability of $4^{\circ} \mathrm{C}$ corresponded to AG (fig. 2a).

\section{Salinity}

Monthly average surface salinity from January 2002 to December 2003 did not show marked changes, only a slight increase from 33.3 to 33.7 (fig. 2b). Lowest salinities were recorded during 2004, the rainiest year during the study period, with an annual precipitation of $401.1 \mathrm{~mm}$ (CICESE Meteorological Observatory; ftp://ftp.cicese.mx/pub/divOC/ocefisica/ vientos/sauzal/MET/). Other low average surface salinities at AG, PI, and SM occurred during the winter of each year, also associated with local runoff during the rainy season. The highest monthly average surface salinity values ranged from 33.58 to 33.68 and were registered from January through November 2003 , with an average precipitation of $18.9 \mathrm{~mm}$.

\section{Dissolved inorganic nitrogen and phosphate}

Dissolved inorganic nitrogen (DIN) and phosphate (DIP), determined as $\mathrm{NO}_{3}^{-}+\mathrm{NO}_{2}^{-}$and $\mathrm{PO}_{4}^{-3}$, respectively, followed a similar pattern at all sites. Average concentrations of $3.31 \mu \mathrm{M}$ valores más bajos $\left(12^{\circ} \mathrm{C}\right.$ en $\mathrm{SM}$ y $14^{\circ} \mathrm{C}$ en $\left.\mathrm{RB}\right)$ se registraron en el invierno cuando la mezcla vertical promovió una temperatura homogénea desde la superficie hasta $20 \mathrm{~m}$ de profundidad. Los valores máximos de temperatura superficial $\left(22^{\circ} \mathrm{C}\right.$ en $\mathrm{SM}$ y $24.5^{\circ} \mathrm{C}$ en $\mathrm{RB}$ ) se registraron durante los periodos de verano, cuando la columna de agua estaba estratificada. La temperatura superficial de invierno-verano presentó una diferencia de $8^{\circ} \mathrm{C}$ a $8.5^{\circ} \mathrm{C}$.

Los perfiles de CTD (datos no mostrados) indican que la BTS se caracterizó por una estratificación térmica durante primavera y verano. Esta estratificación fue muy variable entre las localidades de muestreo. Mientras que SM mostró una columna de agua bien mezclada durante la mayor parte del año, en contraste RB, PI y AG mostraron una columna de agua estratificada durante toda la temporada de primavera-verano. La máxima variabilidad en la temperatura superficial se midió en SM y PI, con un gradiente anual de $9^{\circ} \mathrm{C}$, seguido por RB

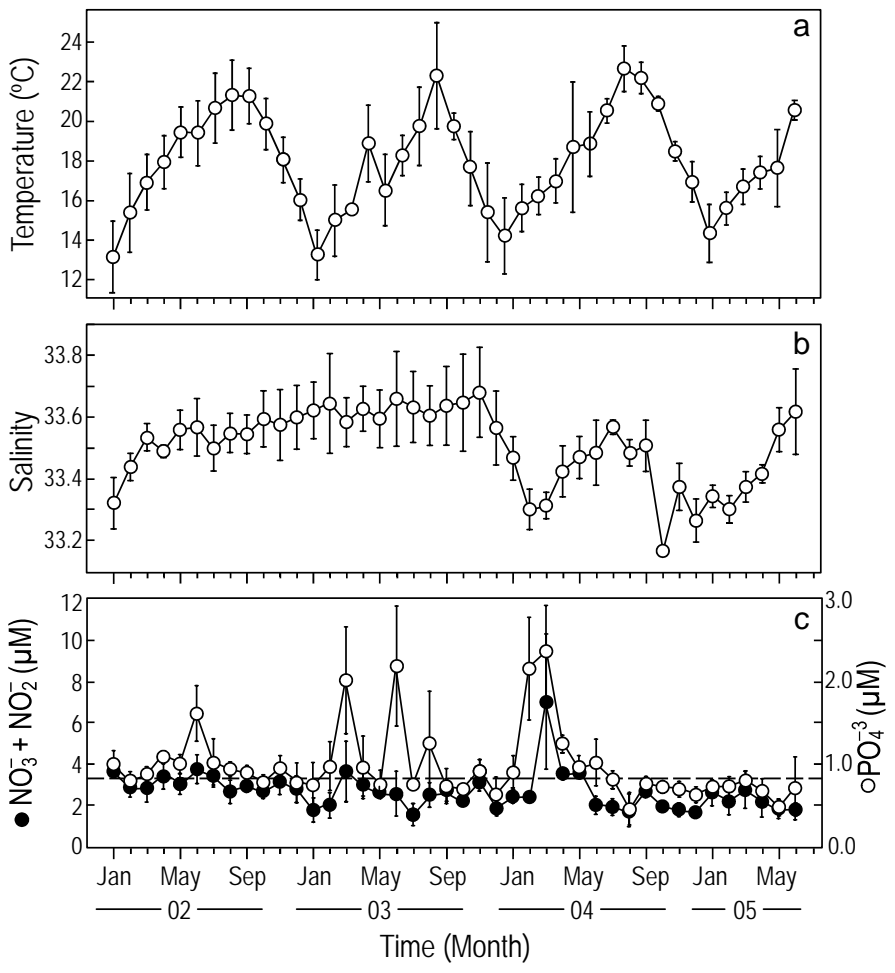

Figure 2. Variability of (a) temperature, (b) salinity, and (c) dissolved inorganic nitrite + nitrate (DIN) and phosphate (DIP) in surface seawater of Todos Santos Bay from January 2002 to June 2005. Note different scales for each nutrient. Each square in the graphs represents the monthly average value for the four sampled sites. Vertical bars represent one standard deviation. In (c), the solid line indicates the mean value of 3.31 $\mu \mathrm{M}$ for DIN and the broken line the mean value of $0.83 \mu \mathrm{M}$ for DIP.

Figura 2 Variabilidad superficial de (a) temperatura, (b) salinidad y (c) nutrientes inorgánicos disueltos (nitrito + nitrato [DIN] y fosfato [DIP]) en la Bahía de Todos Santos durante el periodo enero de 2002 a junio de 2005. Nótese las diferentes escalas para los nutrientes. Cada cuadro en los gráficos representa el valor promedio mensual de los cuatro sitios muestreados. Las barras verticales representan una desviación estándar. En (c) la línea sólida indica el valor promedio de $3.1 \mu \mathrm{M}$ para DIN y la línea discontínua indica el valor medio de $0.83 \mu \mathrm{M}$ para DIP. 
for DIN and $0.83 \mu \mathrm{M}$ for DIP were registered (fig. 2c). Maximum DIN concentrations for all locations ranged from 4.12 to $4.90 \mu \mathrm{M}$ in the early spring, diminishing to $1.20 \mu \mathrm{M}$ during May and June each year. Moreover, erratic increases of DIN were registered in summer, ranging from $4.14 \mu \mathrm{M}$ at $\mathrm{RB}$ to $7.60 \mu \mathrm{M}$ at SM. In contrast to DIN, the DIP values indicated lower concentrations and lesser variability. Maximum values in early spring were also higher than the average, ranging from $0.93 \mu \mathrm{M}$ at $\mathrm{RB}$ to $1.11 \mu \mathrm{M}$ at $\mathrm{SM}$, and from $1.64 \mu \mathrm{M}$ at PI to 7.94 at AG. DIP also showed random increases during the summer of each year, with pulses of smaller magnitude than DIN.

\section{Irradiance}

Subsurface photosynthetic irradiance $\left(\mathrm{E}_{\mathrm{PAR}}\right)$ reached maximum values from May through August of each year, with an average irradiance of $345 \mu \mathrm{mol}$ quanta $\mathrm{m}^{-2} \mathrm{~s}^{-1}$ from 8:00 to 14:00 hours (data not shown). When $\mathrm{E}_{\mathrm{PAR}}$ averaged $125 \mu \mathrm{mol}$ quanta $\mathrm{m}^{-2} \mathrm{~s}^{-1}$ the dinoflagellate blooms were present near the surface.

\section{Dinoflagellate cells and temporary cysts}

Dinoflagellates showed a strong seasonal variability. Common taxa in the water column (0-3 m) were Ceratium, Lingulodinium, Prorocentrum, and Scrippsiella. When dinoflagellate blooms were absent, these genera co-occurred with total cell counts of $10^{2}$ to $10^{4}$ cells $\mathrm{L}^{-1}$. Other major taxa found during summer were Protoperidinium (Bergh), Amphidinium, Gymnodinium, Gyrodinium, and the mikimotoi complex.

Dinoflagellate blooms developed periodically during the spring-summer season. These blooms usually started in April and remained intermittently until August, and exceptionally until September in 2005. Most of these events were dominated by $L$. polyedrum, reaching abundances of $10^{5}$ to $10^{6}$ cells $\mathrm{L}^{-1}$ (fig. 3). These blooms were not always simultaneous at all locations, but they presented a patchy distribution. These patches changed their position during the day in an apparent close relation with the wind stress on the sea surface.

The cyst-forming species $L$. polyedrum and S. trochoidea showed comparable trends in their temporal and spatial variability. During the blooming periods, however, the abundances of $L$. polyedrum were three orders of magnitude greater than those of $S$. trochoidea.

The temporary cysts of $L$. polyedrum showed peak abundances during the blooming period from June to September, when planktonic cells of this species occurred as dense blooms and shortly after the proliferations, with little if any development in other months (fig. 4). Maximum abundances of temporary cysts of $76 \times 10^{3}$ and $50 \times 10^{3}$ cysts $\mathrm{L}^{-1}$ were observed in May 2003 and May 2005, respectively, at PI.

\section{Resting cysts}

Resting cysts of $L$. polyedrum and S. trochoidea (fig. 5) in surface sediments showed a strong seasonal variability at all con un gradiente de $8^{\circ} \mathrm{C}$ y la mínima variabilidad anual de $4^{\circ} \mathrm{C}$ correspondió a AG (fig. 2a).

\section{Salinidad}

El promedio mensual de salinidad superficial de enero de 2002 a diciembre de 2003 no registró fuertes cambios, solamente un ligero aumento de 33.3 a 33.7 en el promedio mensual (fig. 2b). Las salinidades más bajas se registraron durante 2004, el año más lluvioso del periodo de estudio con una precipitación anual de $401.1 \mathrm{~mm}$ (Observatorio Meteorológico de CICESE; ftp://ftp.cicese.mx/pub/divOC/ocefisica/vientos/sauzal/MET/). Otros promedios bajos de salinidad se registraron en AG, SM y PI durante cada invierno, también asociadas con el aporte de los arroyos durante la temporada de lluvias. Los valores más altos del promedio mensual de salinidad superficial oscilaron entre 33.58 y 33.68 y se registraron de enero a noviembre de 2003, con una precipitación media de $18.9 \mathrm{~mm}$.

\section{Nitrógeno y fosfato inorgánicos disueltos}

El nitrógeno y fosfato inorgánicos disueltos determinados como $\mathrm{NO}_{3}^{-}+\mathrm{NO}_{2}^{-}$(DIN) y $\mathrm{PO}_{4}^{-3}$ (DIP), siguieron un patrón similar en todas las localidades. Se registraron concentraciones medias de $3.31 \mu \mathrm{M}$ para el DIN y $0.83 \mu \mathrm{M}$ para el DIP (fig. 2c). Las concentraciones máximas de DIN para todas las localidades oscilaron entre 4.12 y $4.90 \mu \mathrm{M}$ al inicio de la primavera, disminuyendo a $1.20 \mu \mathrm{M}$ durante mayo y junio de cada año. Además, durante el verano se registraron incrementos irregulares de DIN, con concentraciones desde $4.14 \mu \mathrm{M}$ en RB hasta $7.60 \mu \mathrm{M}$ en SM. En contraste con el DIN, el DIP registró menor concentración y menor variabilidad. Los valores máximos al inicio de la primavera también fueron mayores al promedio, desde $0.93 \mu \mathrm{M}$ en RB hasta $1.11 \mu \mathrm{M}$ en SM, y desde $1.64 \mu \mathrm{M}$ en PI hasta 7.94 en AG. El DIP también mostró incrementos aleatorios durante el verano de cada año, con pulsos de menor magnitud que el DIN.

\section{Irradiancia}

$\mathrm{La}$ irradiancia fotosintéticamente disponible $\left(\mathrm{E}_{\mathrm{PAR}}\right)$ en la parte subsuperficial alcanzó valores máximos desde mayo hasta agosto de cada año, con un promedio de $345 \mu \mathrm{mol}$ cuanta $\mathrm{m}^{-2} \mathrm{~s}^{-1}$, entre las 8:00 y 14:00 horas (datos no mostrados). Cuando se presentaron los florecimientos de dinoflagelados cerca de la superficie la $\mathrm{E}_{\mathrm{PAR}}$ media fue de $125 \mu \mathrm{mol}$ cuanta $\mathrm{m}^{-2}$ $\mathrm{s}^{-1}$ en las horas de la mañana.

\section{Células de dinoflagelados y quistes temporales}

Los dinoflagelados mostraron una fuerte variabilidad estacional. Los taxa comunes en la columna de agua $(0-3 \mathrm{~m})$ fueron Ceratium, Lingulodinium, Prorocentrum y Scrippsiella. Cuando no hubo florecimientos estos géneros coexistieron con 


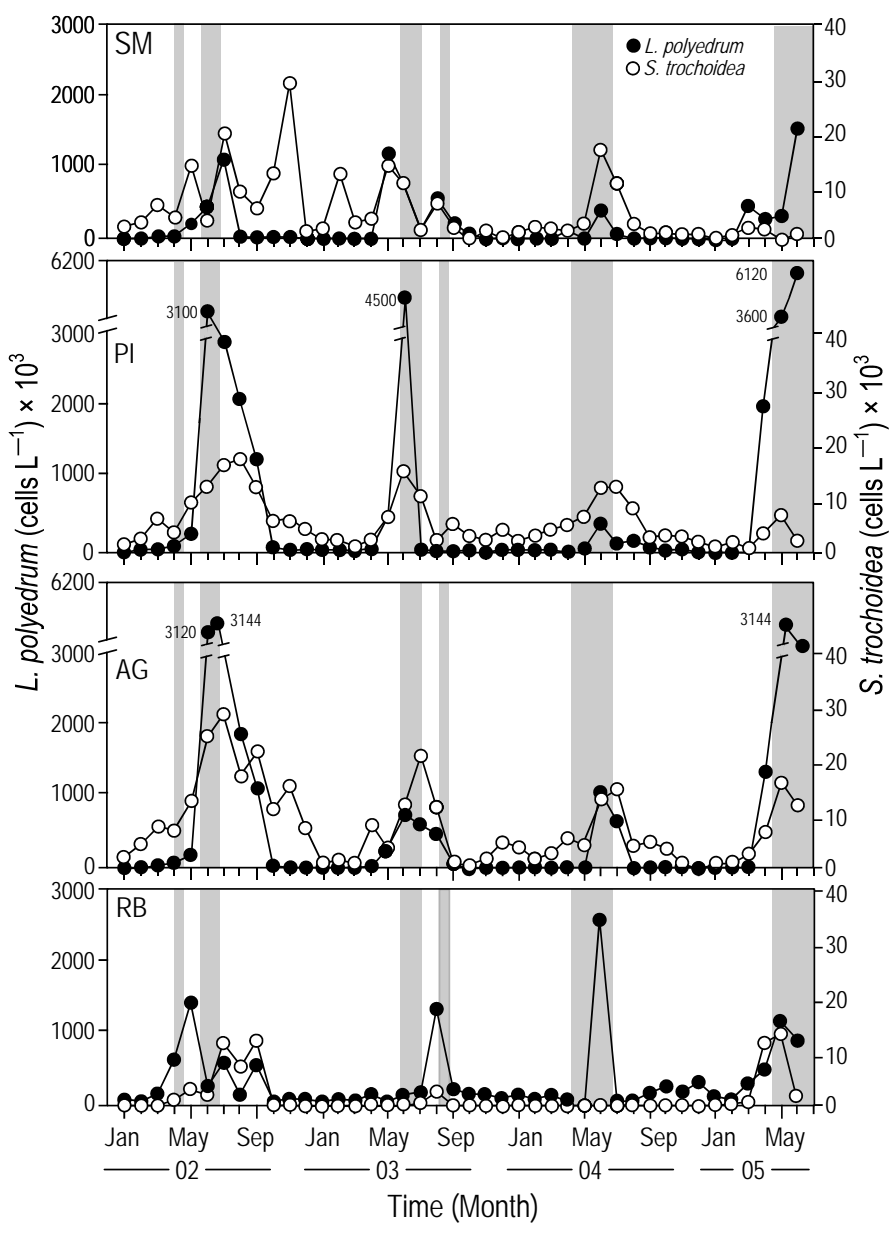

Figure 3. Variability in the abundance of cells (cells $L^{-1}$ ) of Lingulodinium polyedrum (black circles) and Scrippsiella trochoidea (clear circles) in the water column at San Miguel (SM), Puerto Interior (PI), Arroyo El Gallo (AG), and Rincón Ballenas (RB) from January 2002 to June 2005. Note the different scales for each species. Shaded areas indicate when the abundance of dinoflagellate cells was $>10^{5}$ cells $\mathrm{L}^{-1}$ during the study period.

Figura 3. Variabilidad en las abundancias de células (células $\mathrm{L}^{-1}$ ) de Lingulodinium polyedrum (círculos obscuros) y Scrippsiella trochoidea (círculos claros) en la columna de agua para las localidades San Miguel (SM), Puerto Interior (PI), Arroyo El Gallo (AG) y Rincón de Ballenas (RB) durante el periodo enero de 2002 a junio de 2005. Nótese las diferentes escalas para cada especie. Las áreas sombreadas indican cuando las abundancias de células de dinoflagelados fueron $>10^{5}$ células $\mathrm{L}^{-1}$ durante el periodo de estudio.

locations (fig. 6). After the spring-summer period, resting cysts of both species had a strong decrease during the fall-winter of each year. Resting cysts of L. polyedrum reached their maximum in August 2002 (279 cysts $\mathrm{g}^{-1}$ ) and their minimum in January 2004 ( 9 cysts $\left.\mathrm{g}^{-1}\right)$ at SM. Lower abundances of resting cysts for this genus were associated with sea surface temperatures $<17^{\circ} \mathrm{C}$, while the higher abundances were related to sea surface temperatures ranging from $17^{\circ} \mathrm{C}$ to $22.5^{\circ} \mathrm{C}$. The resting cysts of $S$. trochoidea showed a similar trend during the summer months in SM.

The abundance of resting cysts at the other TSB locations ranged from 263 to 970 cysts $\mathrm{g}^{-1}$ for $L$. polyedrum at $\mathrm{RB}$ abundancias totales del orden de $10^{2}$ a $10^{4}$ células $\mathrm{L}^{-1}$. Otros de los principales taxones que ocurrieron durante el verano fueron Protoperidinium (Bergh), Amphidinium, Gymnodinium, Gyrodinium, y el complejo mikimotoi.

Los florecimientos de dinoflagelados se desarrollaron periódicamente durante primavera-verano. Estos florecimientos comúnmente iniciaron en abril y permanecieron con abundancias intermitentes hasta agosto, y de forma excepcional hasta septiembre en 2005. La mayoría de estos eventos fueron dominados por L. polyedrum alcanzando abundancias de $10^{5}$ a $10^{6}$ células $\mathrm{L}^{-1}$ (fig. 3). Estos florecimientos no fueron siempre simultáneos en todas las localidades, pero presentaron una distribución irregular. Sus manchas superficiales cambiaron de posición durante el día en estrecha relación con el esfuerzo del viento sobre la superficie del mar.

Las especies formadoras de quistes $L$. polyedrum y $S$. trochoidea mostraron tendencias comparables en su variabilidad temporal y espacial. Durante los florecimientos L. polyedrum alcanzó abundancias de hasta tres órdenes de magnitud mayores que $S$. trochoidea.

Los quistes temporales de L. polyedrum mostraron abundancias máximas durante los florecimientos de julio a septiembre, cuando las células planctónicas se encontraban en grandes densidades y poco tiempo después de las proliferaciones, con poco o ningún desarrollo en otros meses (fig. 4). Las abundancias máximas de quistes temporales de $76 \times 10^{3}$ y $50 \times 10^{3}$ quistes $\mathrm{L}^{-1}$ se observaron en mayo de 2003 y mayo de 2005 en PI.

\section{Quistes de reposo}

Los quistes de reposo de L. polyedrum y S. trochoidea (fig. $5)$ en los sedimentos superficiales mostraron una fuerte variabilidad estacional en todas las localidades (fig. 6). Después del periodo primavera-verano los quistes de reposo para ambas especies tuvieron una fuerte disminución durante otoñoinvierno de cada año. En SM, los quistes de reposo de $L$. polyedrum alcanzaron su máximo en agosto de 2002 (279 quistes $\mathrm{g}^{-1}$ ) y el mínimo en enero de 2004 ( 9 quistes $\mathrm{g}^{-1}$ ). Las menores abundancias de quistes de reposo para este género se asociaron con una temperatura superficial del mar $<17^{\circ} \mathrm{C}$, mientras que las mayores abundancias correspondieron a temperaturas superficiales en el intervalo de $17^{\circ} \mathrm{C}$ a $22.5^{\circ} \mathrm{C}$. Además, en SM los quistes de reposo de $S$. trochoidea mostraron una tendencia similar durante los meses de verano.

Las abundancias de quistes de reposo en las otras localidades de BTS variaron entre 263 y 970 quistes $\mathrm{g}^{-1}$ para L. polyedrum en $\mathrm{RB}$ y $\mathrm{AG}$, respectivamente; mientras que para $S$. trochoidea los conteos fueron de 13 y 76 quistes $\mathrm{g}^{-1}$ en PI y RB. Las mayores abundancias de quistes de reposo para $L$. polyedrum se encontraron en $\mathrm{RB}$, con una fuerte señal para el máximo durante el verano de cada año (fig. 6), asociado con un promedio de $22^{\circ} \mathrm{C}$ de temperatura superficial, y grandes abundancias de células planctónicas en el intervalo de $1.5 \times 10^{3}$ a 3 $\times 10^{3}$ células $\mathrm{L}^{-1}$. 
and $\mathrm{AG}$, and from 13 to 76 cysts $\mathrm{g}^{-1}$ for $S$. trochoidea at PI and $\mathrm{RB}$, respectively. The highest abundances of $L$. polyedrum resting cysts were found at RB, with a strong signal for the maximum during the summer of each year (fig. 6), associated with high surface water temperatures, averaging $22^{\circ} \mathrm{C}$, and a high abundance of planktonic cells, ranging from $1.5 \times 10^{3}$ to $3 \times$ $10^{3}$ cells $\mathrm{L}^{-1}$. The distribution of resting cysts showed three groups (stress 0.7): the first corresponded to SM, associated with high physical dynamics and coarse sediment size; the second corresponded to RB, with lower dynamic effect and fine sediments; and the third was associated with the finest grain size, represented by PI and AG with a core-like distribution pattern of the resting cysts in surface sediments (fig. 7). Furthermore, ANOSIM showed that the distribution pattern of resting cyst abundances for both species did not differ significantly among PI, AG, and RB ( $p^{* * *}$, global $r=0.236$ ), but there was a significant difference at $\mathrm{SM}\left(p^{*}, r=-0.06\right)$ (table 1).

The MRA revealed that the combination of temperature, DIP, and abundance of temporary cysts together explained $48 \%$ of the variability $\left(r^{2}=0.48, p^{* * *}, \alpha=0.05\right)$ for the abundances of $L$. polyedrum resting cysts in surface sediments. Additionally, $54 \%$ of the variability of temporary cysts in the water column could be explained only by the abundance of planktonic cells $\left(r^{2}=0.54, p^{* * *}, \alpha=0.05\right)$, while other environmental factors did not show any close relationship. The MRA for the $S$. trochoidea resting cysts showed no significant statistical relationship with the environmental factors considered in this study.

\section{Discussion}

It has been shown that $L$. polyedrum dominates the cyst assemblage in TSB, and that the strong seasonality of the resting cysts of this species is associated mainly with surface water temperature (Peña-Manjarrez et al. 2005). According to our observations, L. polyedrum blooms in TSB usually started when the sea surface temperature was between $17^{\circ} \mathrm{C}$ and $22.5^{\circ} \mathrm{C}$, suggesting that this "thermal window" drives this dinoflagellate species during the different stages of its life cycle in the bay. In laboratory cultures, Band-Smith et al. (2004) found that the optimal temperature range for the growth of Gymnodinium catenatum was from $11.5^{\circ} \mathrm{C}$ to $30^{\circ} \mathrm{C}$, with highest growth rates between $21^{\circ} \mathrm{C}$ and $29^{\circ} \mathrm{C}$.

In germination experiments, Anderson (1980) found that a water temperature of $22^{\circ} \mathrm{C}$ led to a rapid development of the hypnozygote in Gonyaulax tamarensis $(=$ Alexandrium tamarense), with germination possible one month after formation. Cysts formed during the late spring in temperate waters are thus capable of excystment several months later as fall temperatures decrease; those formed in the fall take longer to mature, but are viable after six months of overwintering (Anderson 1980). Alternating spring and fall blooms seeded by germinating populations of dormant cysts are thus possible.
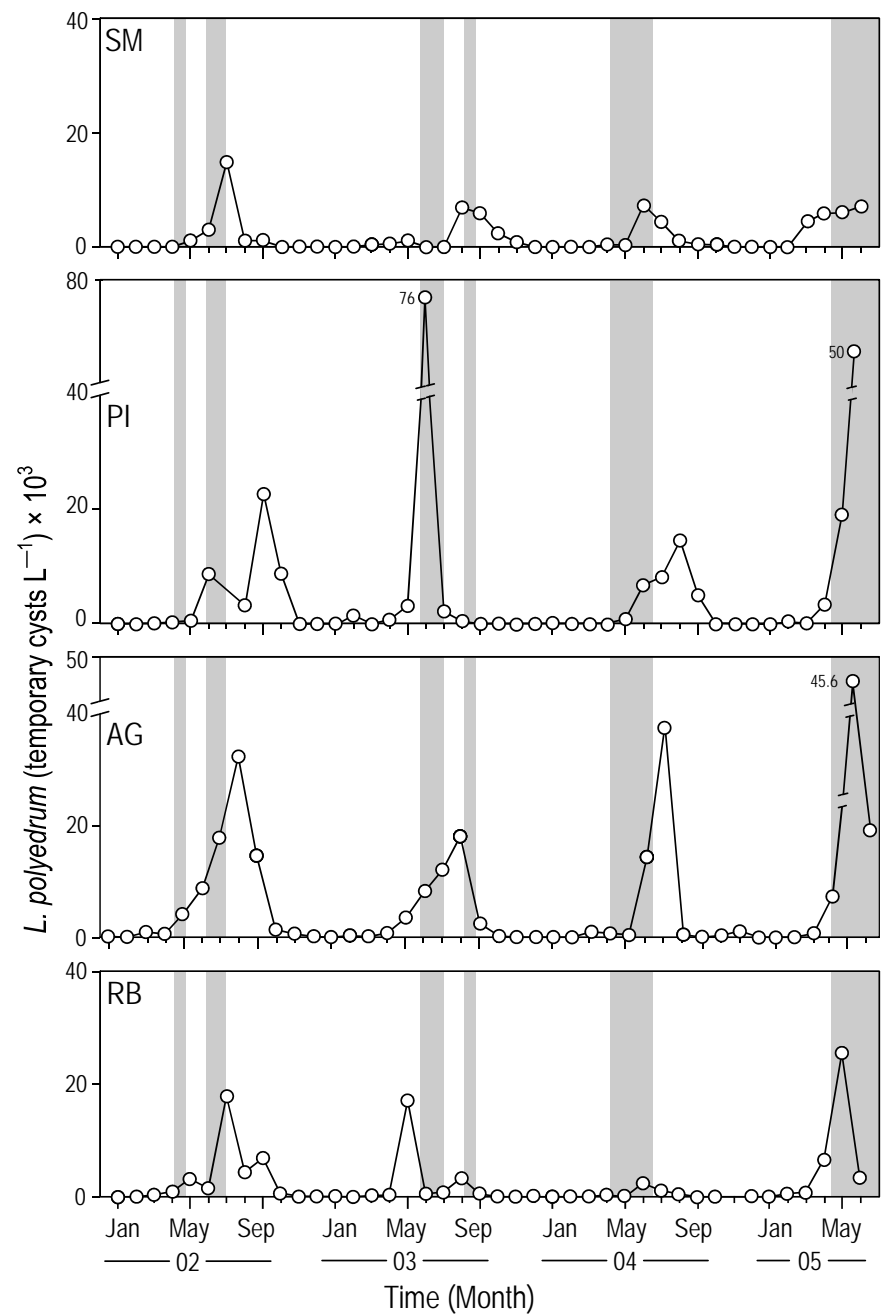

Figure 4. Variability of the abundance of temporary cysts (cysts $L^{-1}$ ) for Lingulodinium polyedrum in the water column at San Miguel (SM), Puerto Interior (PI), Arroyo El Gallo (AG), and Rincón Ballenas (RB) from January 2002 to June 2005. Shaded areas indicate when the abundance of dinoflagellate cells was $>10^{5}$ cells $\mathrm{L}^{-1}$ during the study period.

Figura 4. Variabilidad de las abundancias de quistes temporales (quistes $\mathrm{L}^{-1}$ ) para Lingulodinium polyedrum en la columna de agua para las localidades San Miguel (SM), Puerto Interior (PI), Arroyo El Gallo (AG) y Rincón de Ballenas (RB) durante el periodo enero de 2002 a junio de 2005. Las áreas sombreadas indican cuando las abundancias de células de dinoflagelados fueron $>10^{5}$ células $\mathrm{L}^{-1}$ durante el periodo de estudio.

La distribución de quistes de reposo mostró tres grupos (estrés 0.7): el primero correspondió a SM, asociado con la intensa dinámica física y sedimento grueso; un segundo grupo perteneció a RB con menor efecto dinámico y sedimentos finos; y el tercero asociado con los sedimentos más finos. El último grupo estuvo representado por PI y AG, con un patrón de distribución de los quistes de reposo similar a un núcleo en los sedimentos superficiales (fig. 7). El ANOSIM mostró que el patrón de distribución de las abundancias de los quistes de reposo para ambas especies no tuvo diferencias significativas entre las localidades PI, AG y RB $\left(p^{* * *}, r\right.$ global $\left.=0.236\right)$, 

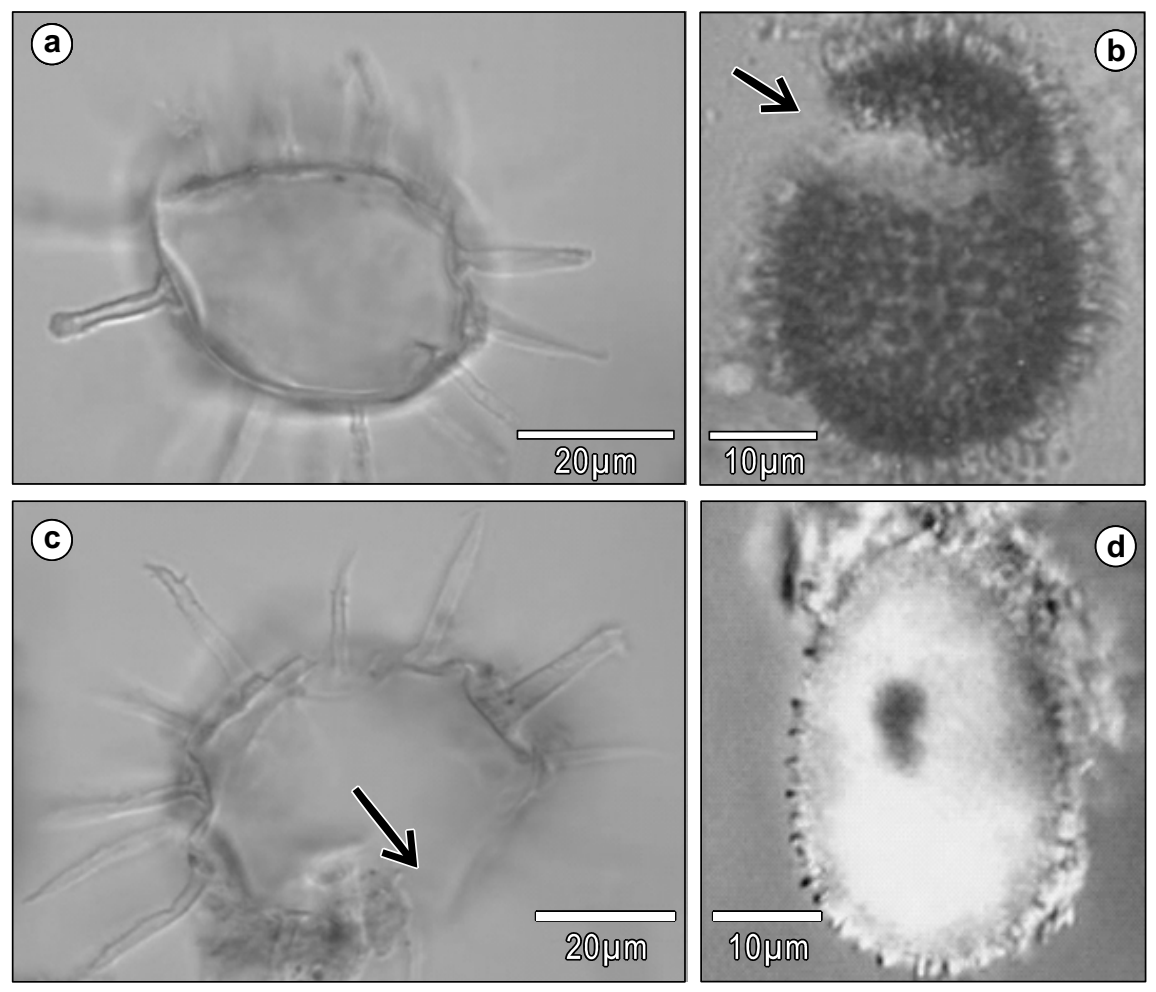

Figure 5. Photomicrographs of resting cysts in surface sediments of Todos Santos Bay. Lingulodinium polyedrum viable cyst (a) and nonliving cyst (c). Scrippsiella trochoidea nonliving cyst (b) and viable cyst (d). White arrows in photomicrographs (b) and (c) indicate the archeopile in each specimen.

Figura 5. Fotomicrografías de los quistes de reposo en los sedimentos de la Bahía de Todos Santos. Quiste viable (a) y quiste no viable (c) de Lingulodinium polyedrum. Quiste no viable (b) y quiste viable (d) de Scrippsiella trochoidea. Las flechas en las fotomigrafías (b) y (c) muestran el arqueópilo en cada espécimen. Las barras de escala representan $20 \mu \mathrm{m}$ para L. polyedrum y $10 \mu \mathrm{m}$ para S. trochoidea.

Average nutrient concentrations were $3.31 \mu \mathrm{M}$ for DIN and $0.83 \mu \mathrm{M}$ for DIP; however, preceding the bloom events and during the spring of each year, except for 2005, both nutrients showed an important increase, especially DIP, which reached twofold or slightly higher concentrations than the average value (fig. 2c). It seems that these nutrient inputs were related to the initiation of the dinoflagellate bloom events, which usually started in spring and continued through summer.

The lowest nutrient concentrations were recorded from August 2004 to May 2005, although in March 2005 there was a pero si hubo una diferencia significativa para $\mathrm{SM}\left(p^{*}, r=\right.$ -0.06 ) (tabla 1).

El ARM mostró que el efecto combinado de la temperatura, el DIP y las abundancias de quistes temporales explicaron el $48 \%$ de la variabilidad $\left(r^{2}=0.48, p^{* * *}, \alpha=0.05\right)$ para las abundancias de los quistes de reposo de L. polyedrum en los sedimentos superficiales. Además, $54 \%$ de la variabilidad de quistes temporales en la columna de agua se explicó por la abundancia de células planctónicas $\left(r^{2}=0.54, p^{* * *}, \alpha=0.05\right)$, mientras que los otros factores ambientales no mostraron

Table 1 Multiple regression analysis $(\alpha=0.05)$ for the abundance of resting and temporary cysts of Lingulodinium polyedrum against environmental factors and biological variables.

Tabla 1 Análisis de regresión múltiple $(\alpha=0.05)$ para la abundancia de quistes de reposo y temporales de Lingulodinium polyedrum contra los factores ambientales y las variables biológicas.

\begin{tabular}{|c|c|c|c|c|}
\hline & \multicolumn{3}{|c|}{$\begin{array}{l}\text { Lingulodinium polyedrum } \\
\text { resting cyst abundance }\end{array}$} & \multirow{2}{*}{$\begin{array}{c}\text { L. polyedrum } \\
\text { temporary cyst abundance } \\
\text { Planktonic cells }\end{array}$} \\
\hline & Temperature & $\mathrm{PO}_{4}^{-3}$ & Temporary cysts & \\
\hline $\bar{\beta}$ & 0.669 & 0.259 & 0.206 & 0.738 \\
\hline$r^{2}$ & & 0.48 & & 0.540 \\
\hline$P$ value & & $<0.001$ & & $<0.001$ \\
\hline$F$ value & & 11.95 & & 118.19 \\
\hline
\end{tabular}



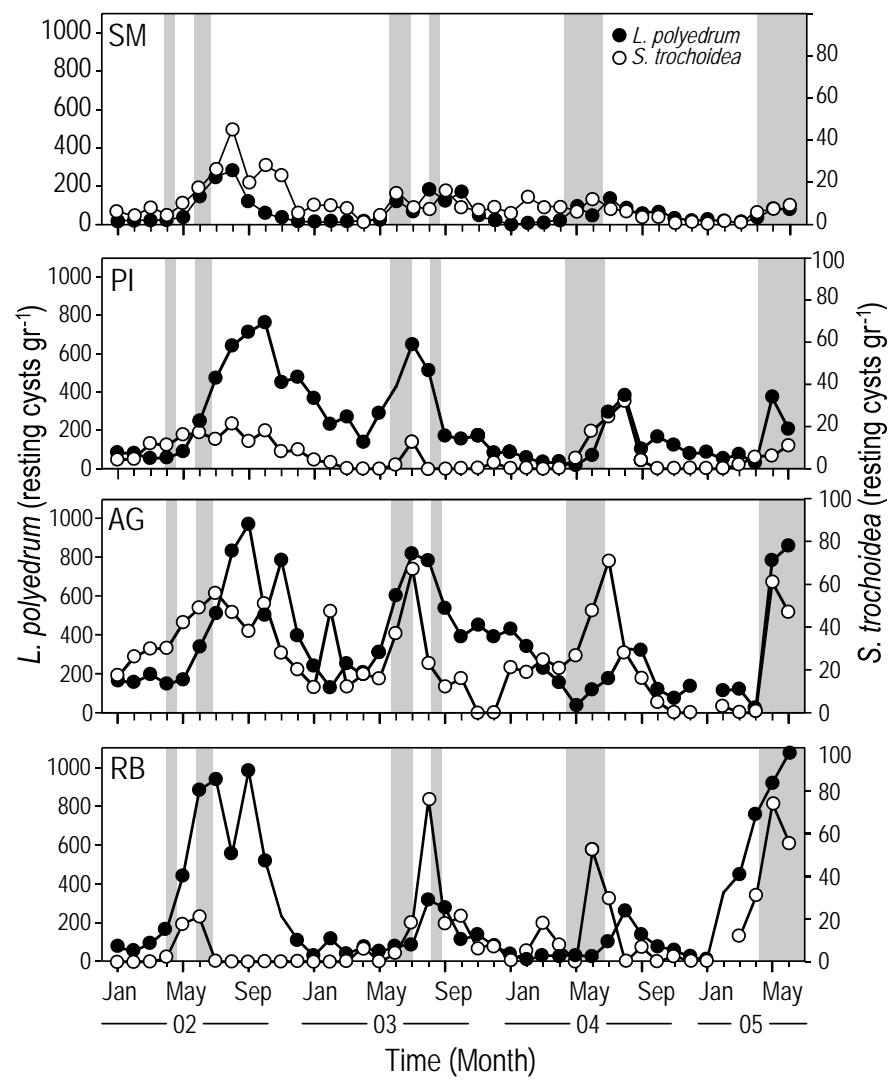

Figure 6. Variability of the abundance of resting cysts (cysts $\mathrm{g}^{-1}$ of sediment dry weight) for Lingulodinium polyedrum and Scrippsiella trochoidea at San Miguel (SM), Puerto Interior (PI), Arroyo El Gallo (AG), and Rincón Ballenas (RB) from January 2002 to June 2005. Note the different scales for each species. Shaded areas indicate when the abundance of dinoflagellate cells was $>10^{5}$ cells $\mathrm{L}^{-1}$ during the study period.

Figura 6. Variabilidad de las abundancias de quistes de reposo (quistes $\mathrm{g}^{-1}$ de sedimento en peso seco) para Lingulodinium polyedrum y Scrippsiella trochoidea en San Miguel (SM), Puerto Interior (PI), Arroyo El Gallo (AG) y Rincón de Ballenas (RB) durante el periodo enero de 2002 a junio de 2005. Nótese las diferentes escalas para cada especie. Las áreas sombreadas indican cuando las abundancias de células de dinoflagelados fueron $>10^{5}$ células $\mathrm{L}^{-1}$ durante el periodo de estudio.

slight increase. The longest lasting dinoflagellate bloom registered at TSB began in April 2005, with a high abundance of thecate species ( $P$. micans, C. furca, and L. polyedrum). In June, the dinoflagellate assemblage changed and was represented mainly by naked genera (Amphidinium sp., Gyrodinium sp., Gymnodinium sp., and the mikimotoi complex species). This bloom developed from April to September with intermittent cell abundances, but in June when the bloom was in a declining period, DIN reached values of $7.6 \mu \mathrm{M}$ at SM, whilst DIP maintained concentrations lower than $0.67 \mu \mathrm{M}$. These conditions allowed the bloom to recover high cell abundances. This recovery of the bloom in June 2005 can be attributed to the fact that the hours of daylight $(14.15 \mathrm{~h})$ and the surface water temperature $\left(20.7^{\circ} \mathrm{C}\right)$ were appropriate to promote the growth of dinoflagellate cells.

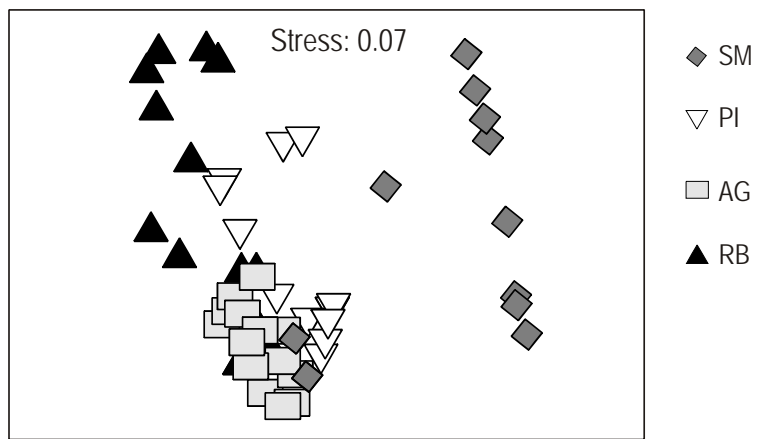

Figure 7. Multidimensional scaling ordination from $\log (x+1)$ for transformed monthly average cyst abundances (cysts $\mathrm{g}^{-1}$ of sediment dry weight) for Lingulodinium polyedrum at San Miguel (SM), Puerto Interior (PI), Arroyo El Gallo (AG), and Rincón Ballenas (RB) from January 2002 to June 2005.

Figura 7. Arreglo del análisis multidimensional escalado MDE a partir de la transformación $\log _{10}(x+1)$ del promedio mensual en las abundancias de quistes de reposo (quistes $g^{-1}$ de sedimento en peso seco) para Lingulodinium polyedrum en San Miguel (SM), Puerto Interior (PI), Arroyo El Gallo (AG) y Rincón de Ballenas (RB) durante el periodo enero de 2002 a junio de 2005.

ninguna relación. El ARM para los quistes de reposo de $S$. trochoidea no mostró relación estadísticamente significativa con los factores ambientales considerados en este estudio.

\section{Discusión}

Se ha demostrado que L. polyedrum domina la composición del conjunto de quistes en BTS, y que la fuerte estacionalidad de los quistes de reposo de esta especie se asocia principalmente con la temperatura superficial (Peña-Manjarrez et al. 2005). De acuerdo con nuestras observaciones, los florecimientos de $L$. polyedrum en la BTS generalmente iniciaron cuando la temperatura superficial del mar se encontró entre $17^{\circ} \mathrm{C}$ y $22.5^{\circ} \mathrm{C}$, sugiriendo que esta "ventana térmica" controla las diferentes etapas del ciclo de vida de la especie. Para Gymnodinium catenatum, Band-Smith et al. (2004) en cultivos encontraron que el intervalo óptimo de temperatura para su crecimiento fue de $11.5^{\circ} \mathrm{C}$ a $30^{\circ} \mathrm{C}$ con tasas máximas de crecimiento entre $21^{\circ} \mathrm{C}$ y $29^{\circ} \mathrm{C}$.

En experimentos de germinación, Anderson (1980) encontró que la temperatura de $22^{\circ} \mathrm{C}$ condujo a un rápido desarrollo del hipnocigoto de Gonyaulax tamarensis (= Alexandrium tamarense), con la posible germinación un mes después de su formación. Los quistes formados en aguas templadas al final de la primavera son capaces de exquistar varios meses después conforme la temperatura de otoño disminuye; los quistes formados en el otoño requieren más tiempo para madurar pero son viables después de seis meses de invernación (Anderson 1980). Esto hace posible la ocurrencia de florecimientos alternados en primavera y otoño alimentados por poblaciones semilla de quistes de reposo.

Las concentraciones medias de nutrientes fueron de 3.31 $\mu \mathrm{M}$ para el DIN y de $0.83 \mu \mathrm{M}$ para el DIP. Sin embargo, antes de los florecimientos y durante la primavera de cada año, a 
Different local sources of DIP and DIN exist in TSB: coastal upwelling waters transported to the inner bay (Espinosa-Carreón 2001, Segovia-Zavala et al. 2007), sewage from the city of Ensenada (Segovia-Zavala et al. 1988), runoff during the rainy season, debris from tuna farms, and oyster and mussel cultures. Altogether they contribute to maintain DIP and DIN at non-limiting concentrations for the development of blooms.

According to the nutrient eutrophication index (NEI), in TSB the eutrophic areas influenced by sewage outfall (AG) received higher index scores (NEI $>5$ ) for DIN. These scores decreased to mesotrophic levels (5-3) at RB, PI, and SM. Oligotrophic areas of DIN (NEI $<3)$ were not present in TSB. The NEI for DIP represented mesotrophic conditions for AG, and oligotrophic characteristics for PI, RB, and SM. These indexes suggest that nutrients within TSB are virtually unlimited for dinoflagellate growth.

The average stoichiometry for the N:P ratios at all locations was from 4.0 to 9.67 , indicating that the phosphates were always higher than the Redfield ratios for these nutrients in the natural marine environment ( $\mathrm{N}: \mathrm{P}=16: 1)$. The biogeochemical budget for DIP and DIN indicates that the ecosystem acts as a sink of both DIP and DIN. Therefore, on an annual basis, TSB can be considered an autotrophic system because the nutrient concentration associated with organic matter production is related to the development of dense and recurrent dinoflagellate blooms.

The highest production of resting cysts occurred during and after the spring-summer bloom events. Once the production of resting cysts had initiated, it continued throughout the bloom, including the maintenance and decline phases. Massive encystment of planktonic cells occurred at the end of the bloom period in each year. A similar process has been reported for $S$. trochoidea in batch cultures (Wang et al. 2006) and natural waters (Joyce and Pitcher 2004).

After the resting cysts are formed in the water column, their settlement velocity is controlled by their physical characteristics, especially size, density, and shape. The cysts of $S$. trochoidea have a density of $1.32 \mathrm{~g} \mathrm{~cm}^{-3}$, while those of Gonyaulax tamarensis (a gonyaulacoid like L. polyedrum) have a density of $1.24 \mathrm{~g} \mathrm{~cm}^{-3}$, and the estimated settling velocities are $0.013 \mathrm{~cm} \mathrm{~s}^{-1}$ for the former and $0.015 \mathrm{~cm} \mathrm{~s}^{-1}$ for the latter (Anderson et al. 1985). Since average seawater density in TSB is $1.026 \mathrm{~g} \mathrm{~cm}^{-3}$ (García-Córdova et al. 2005), without the influence of any physical process that produces vertical mixing, the cysts of both species may reach the surface sediments in a few hours and remain there until a strong physical disturbance in the water column removes them. Our observations show that after settlement, resting cysts may be transported to other areas where the current velocity weakens, resulting in a depositional environment. One or more of the following mechanisms might be involved in this transportation: (1) sufficient vertical mixing to remove the cysts from the bottom, even excepción de 2005, ambos nutrientes tuvieron un incremento importante, especialmente el DIP que alcanzó el doble o un poco más del doble de la concentración media (fig. 2c). Parece ser que estos aportes de nutrientes estuvieron relacionados con el inicio de los florecimientos de dinoflagelados, que generalmente empiezan en la primavera y continúan durante el verano.

De agosto de 2004 a mayo de 2005 las concentraciones de nutrientes registraron los valores más bajos, aunque en marzo de 2005 se registró un ligero incremento. En abril de 2005 inició el florecimiento de dinoflagelados de mayor duración que se haya registrado en la BTS, con grandes abundancias de especies tecadas (P. micans, C. furca y L. polyedrum). Durante junio la composición de dinoflagelados cambió, estando representado principalmente por géneros atecados (Amphidinium spp., Gyrodinium spp., Gymnodinium spp. y especies del complejo mikimotoi). Este florecimiento se desarrolló de abril a septiembre, con abundancias celulares intermitentes, pero en junio, cuando el florecimiento se encontraba en un periodo de decaimiento, el DIN alcanzó valores de $7.6 \mu \mathrm{M}$ en SM, mientras que el DIP mantuvo concentraciones inferiores a $0.67 \mu \mathrm{M}$. Estas condiciones promovieron la recuperación de grandes abundancias celulares. La recuperación del florecimiento en junio de 2005 puede explicarse debido a que las horas de luz durante el día $(14.15 \mathrm{~h})$ y la temperatura superficial $\left(20.7^{\circ} \mathrm{C}\right)$ fueron las apropiadas para promover el crecimiento de estas especies de dinoflagelados.

Existen diferentes fuentes locales de DIP y DIN en la BTS: agua de surgencias costeras transportadas al interior de la bahía (Espinosa-Carreón et al. 2001, Segovia-Zavala et al. 2007); aguas residuales vertidas desde la ciudad de Ensenada (Segovia-Zavala et al. 1988); escorrentías durante la temporada de lluvias; desechos de las granjas de atún, así como los cultivos de mejillón y ostión. En conjunto estos flujos contribuyen a mantener altas concentraciones de DIN y DIP, por lo que en consecuencia no existen limitaciones de estos recursos para el desarrollo de los florecimientos.

De acuerdo con el índice de eutroficación por nutrientes (IEN), en la BTS las aéreas influenciadas por descargas de aguas residuales $(\mathrm{AG})$ recibieron las puntajes más altos (IEN > 5) para el DIN. Estos puntajes disminuyeron a niveles mesotróficos (3-5) en PI, RB y SM. En BTS no se encontraron áreas oligotróficas en DIN (IEN < 3). El IEN para el DIP presentó condiciones mesotróficas en AG y oligotróficas en PI, RB y $\mathrm{SM}$. Estos índices sugieren que dentro de la BTS los nutrientes son prácticamente ilimitados para el crecimiento de los dinoflagelados.

La estequiometría media para las razones $\mathrm{N}: \mathrm{P}$ en todas las localidades estuvo entre 4.0 y 9.67, lo que indica que los fosfatos siempre se encontraron en concentraciones superiores a las proporciones de Redfield en el medio marino natural $(\mathrm{N}: \mathrm{P}=$ 16:1). El balance biogeoquímico de DIN y DIP indica que el ecosistema funciona como un sumidero para ambos tipos de nutrientes. Sobre una base anual la BTS puede ser considerada como un sistema "autotrófico" dado que la concentración de nutrientes asociada con la producción de materia orgánica se 
during the spring-summer season; (2) tidal flux carrying fine particles close to the shoreline; and (3) cysts resuspended in the water column and exposed to horizontal advection.

The highest cyst abundances found at RB were associated with the sediment size fraction of that site $(31-125 \mu \mathrm{m})$, which includes the average size of the resting cysts of $L$. polyedrum $(58 \mu \mathrm{m})$ and $S$. trochoidea $(46 \mu \mathrm{m})$. On the other hand, the higher quantities of resting cysts found at PI and AG during the spring of each year may be related to the fine silt and muddy fractions, with grain sizes between 15 and $31 \mu \mathrm{m}$, as well as to the shallow depths at these locations $(10$ and $12 \mathrm{~m}$, respectively). These observations concur with the results reported by Hoorn (1997), who found that palynomorph abundances, including marine dinoflagellates, seem to be slightly higher in mud samples and lower in sandy-mud environments.

As PI and AG are close to one another and have similar characteristics, we expected to find a comparable abundance of resting cysts at both sites. The lower amounts of S. trochoidea resting cysts at PI may be explained by the presence of $\mathrm{H}_{2} \mathrm{~S}$, which in addition to the lack of benthic organisms suggests that anoxic conditions are present with low sulphur and high ammonia concentrations, and $\mathrm{pH}$ values as low as 4.5 (Carreón-Martínez et al. 2002). This environment may cause chemical weathering of the calcareous outer wall of $S$. trochoidea cysts, which should be sensitive to the acids produced in anoxic sediments (Montresor et al. 1994, Persson and Rosenberg 2003).

To determine the quantity of resting cysts available to seed a new bloom, an average excystment viability of $50 \%$ was used for L. polyedrum (Lewis et al. 1999). We also determined that the dry weight of $1 \mathrm{~m}^{2}$ of the first $2 \mathrm{~cm}$ was $34 \mathrm{~kg}$ for the sandy fraction and $10 \mathrm{~kg}$ for the sandy-mud sediments in TSB. Hence, if the lower average abundances of $L$. polyedrum resting cysts were 62 cysts $\mathrm{g}^{-1}$ in the sandy sediments of SM and 356 cysts $\mathrm{g}^{-1}$ in the muddy bed at AG, these sites would yield $1.05 \times 10^{6}$ and $1.78 \times 10^{6}$ resting cysts $\mathrm{m}^{-2}$, respectively.

In contrast, $S$. trochoidea resting cysts, for which a final germination ratio of $40-50 \%$ has been estimated in natural waters (Wang et al. 2007), would yield $0.081 \times 10^{6}$ and $0.99 \times 10^{6}$ germinal cells $\mathrm{m}^{-2}$ at $\mathrm{SM}$ and $\mathrm{AG}$, respectively. These quantities of $L$. polyedrum and $S$. trochoidea resting cysts are high enough to seed the water column and initiate a new bloom at least along the coastal fringe of TSB.

Both MDS and ANOSIM confirmed that there were three groups of sedimentary environments associated with the abundance of resting cysts. This assemblage is clearly associated with the sediment size described for TSB (Emery et al. 1957, Barrera-Gaona 1998): coarse to fine sands $(\varnothing=1-3)$ at SM, fine sands to coarse silts ( $\varnothing=4-5)$ at RB, and a muddy fraction $(\varnothing=5-6)$ at AG and PI.

The homogeneity of variance among RB, PI, and AG, together with the heterocedasticity found at SM confirm that the abundance of resting cysts is strongly driven by physical relaciona con el desarrollo florecimientos densos y recurrentes de dinoflagelados.

La mayor producción de quistes de reposo ocurrió durante y después de los florecimientos de primavera-verano. Una vez que inició la producción de quistes de reposo, ésta continúa durante todo el florecimiento incluyendo las fases de mantenimiento y decaimiento. Al final del periodo de florecimientos de cada año ocurre un enquistamiento masivo de las células planctónicas. Para S. trochoidea se han reportado procesos similares en cultivos estacionarios (Wang et al. 2006) y en condiciones naturales (Joyce y Pitcher 2004).

Después de que los quistes de reposo se forman en la columna de agua, su velocidad de asentamiento es controlada por sus características físicas, especialmente el tamaño, la densidad y la forma. Los quistes de S. trochoidea tienen una densidad de $1.32 \mathrm{~g} \mathrm{~cm}^{-3}$, mientras que Gonyaulax tamarensis (un Gonyaulacoideo similar a $L$. polyedrum) tiene una densidad de $1.24 \mathrm{~g} \mathrm{~cm}^{-3}$, y las velocidades de asentamiento estimadas son de $0.013 \mathrm{~cm} \mathrm{~s}^{-1}$ para el primero y $0.015 \mathrm{~cm} \mathrm{~s}^{-1}$ para el último (Anderson et al. 1985). Dado que la densidad media del agua de mar en la BTS es $1.026 \mathrm{~g} \mathrm{~cm}^{-3}$ (García-Córdova et al. 2005), sin la presencia de algún proceso físico que promueva la mezcla vertical, los quistes de ambas especies pueden llegar a los sedimentos superficiales en pocas horas y permanecer allí hasta presentarse una intensa perturbación física en la columna de agua. Nuestras observaciones mostraron que después del asentamientos los quistes de reposo pueden ser transportados hacia otras áreas, donde disminuye la velocidad de las corrientes dando lugar a un ambiente depositacional. Uno o varios de los siguientes mecanismos podrían estar implicados en este transporte: (1) la mezcla vertical es suficiente para remover los quistes del fondo, incluso durante la primavera-verano; (2) el flujo de marea transporta las partículas finas cerca de la costa; o (3) los quistes son resuspendidos en la columna de agua y quedan expuestos a la advección horizontal.

La mayor abundancia de quistes encontrados en RB estuvo asociada con la fracción de tamaño de los sedimentos en esa localidad (31 a $125 \mu \mathrm{m}$ ), que incluye el tamaño medio de los quistes de reposo de L. polyedrum $(58 \mu \mathrm{m})$ y $S$. trochoidea (46 $\mu \mathrm{m})$. Por otro lado, las grandes cantidades de quistes de reposo encontradas en PI y AG durante la primavera de cada año pueden estar relacionadas tanto con la fracción de arcillas finas y lodos con tamaños de 15 a $31 \mu \mathrm{m}$, y lo somero de esas localidades (10 y $12 \mathrm{~m}$, respectivamente). Estas observaciones concuerdan con los resultados reportados por Hoorn (1997), quien determinó que las abundancias de palinomorfos, incluyendo a los dinoflagelados marinos, son ligeramente mayores en las muestras de lodos y menores en las muestras areno-lodosas.

Como PI y AG son localidades cercanas con características similares, se esperaba encontrar abundancias comparables de quistes de reposo en ambos sitios. Sin embargo, las menores cantidades de $S$. trochoidea en PI pueden explicarse por la presencia de $\mathrm{H}_{2} \mathrm{~S}$, que además de la ausencia de organismos bentónicos sugiere la presencia de condiciones anóxicas con 
factors. This suggests a size sorting of the organic particles according to the sedimentary environment of TSB as discussed by Walton (1955).

\section{Acknowledgements}

We gratefully acknowledge financial support from the Coordinación Sectorial de Desarrollo Académico (COSDAC) and the Dirección General de Educación en Ciencia y Tecnología del Mar (DGECyTM) through project 910.06-P. Field and laboratory work was partially funded by SEMARNAT through project 2004-COI-62. The first author acknowledges receipt of a scholarship from CONACYT and SEMARNAT. We thank P Chagoya-Loli, L Lafarga-Cosio and M Ortega (CETMAR, Ensenada), V Acosta-Chamorro (SEMAR), and Z Mijangos-Alquisires (DGECyTM) for their help in the field and laboratory work. We also thank two anonymous reviewers and $\mathrm{H}$ Maske for their comments and recommendations to the final version of this work, as well as JM Domínguez and F Ponce for the figures.

\section{References}

Álvarez-Sánchez LG, Hernández-Walls R, Durazo-Arvizu R. 1988. Drift patterns of Lagrangian tracers in Todos Santos Bay. Cienc. Mar. 14: 135-162.

Anderson DM. 1980. Effects of temperature conditioning on development and germination of Gonyaulax tamarensis (Dinophyceae) hypnozygotes. J. Phycol. 16: 166-72.

Anderson DM, Chisholm SW, Watras CJ. 1983. Importance of life cycle events in the population dynamics of Gonyaulax tamarensis. Mar. Biol. 76: 179-189.

Anderson DM, Lively JJ, Reardon EM, Price CA. 1985. Sinking characteristics of dinoflagellate cysts. Limnol. Oceanogr. 30: 1000-1009.

Anderson DM, Fukuyo Y, Matsuoka K. 2003. Cyst methodologies. In: Hallegraeff GM, Anderson DM, Cembella AD (eds.), Manual on Harmful Marine Microalge. UNESCO, Paris, pp. 165-189.

Band-Schmidt C, Morquecho L, Lechuga-Déveze CH, Anderson DM. 2004. Effects of growth medium, temperature, salinity and seawater source on the growth of Gymnodinium catenatum (Dinophyceae) from Bahía Concepción, Gulf of California, Mexico. J. Plankton Res. 26: 1459-1470.

Barrera-Gaona JA. 1998. Patrón de dispersión de sedimentos en la Bahía de Todos Santos, BC. Tesis de maestría, Facultad de Ciencias Marinas, UABC, Ensenada, BC. 54 pp.

Carreón-Martínez LB, Huerta-Díaz MA, Nava-López C, SequeirosValencia A. 2002. Levels of reactive mercury and silver in sediments from the port of Ensenada, Baja California, Mexico. Bull. Environ. Contam. Toxicol. 68: 138-147.

Cembella AD, Turgeon J, Theriault JC, Béland P. 1988. Spatial distribution of Protogonyaulax tamarensis resting cysts in nearshore sediments along the north coast of the lower St. Lawrence Estuary. J. Shellfish Res. 7: 597-609.

Clarke KR, Green RH. 1988. Statistical design and analysis for a "biological effects" study. Mar. Ecol. Prog. Ser. 46: 226-231.

Dale B. 1983. Dinoflagellate resting cysts: "benthic plankton". In: Fryxell GA (ed.), Survival Strategies of the Algae. Cambridge Univ. Press, Cambridge, pp. 69-136.

Emery KO, Gorsline DS, Terry RD, Uchupi E. 1957. Sediments of three bays of Baja California [Mexico]: Sebastian Viscaino, San Cristobal and Todos Santos. J. Sediment. Res. 27: 95-115. altas concentraciones de amonio y bajo contenido de azufre, y valores de pH hasta 4.5 (Carreón-Martínez et al. 2002). Este ambiente puede causar intemperismo químico de las paredes calcáreas de los quistes de $S$. trochoidea, las cuales deben ser sensibles a los ácidos producidos en los sedimentos anóxicos donde podrían ser disueltas (Montresor et al. 1994, Persson y Rosenberg 2003).

Para determinar los quistes de reposo disponibles como semilla para iniciar un nuevo florecimiento se realizó una estimación considerando una viabilidad de exquistamiento media del 50\% para L. polyedrum (Lewis et al. 1999). Además, se determinó que el peso seco de $1 \mathrm{~m}^{2}$ de los primeros $2 \mathrm{~cm}$ de la fracción arenosa es de $34 \mathrm{~kg}$ y de $10 \mathrm{~kg}$ para los sedimentos fango-arenosos de la BTS. Entonces, si las menores abundancias de L. polyedrum fueron de 62 quistes $\mathrm{g}^{-1}$ en los sedimentos arenosos de SM, y de 356 quistes $\mathrm{g}^{-1}$ en el fango de AG, estas localidades aportarían $1.05 \times 10^{6}$ y $1.78 \times 10^{6}$ quistes de reposo $\mathrm{m}^{-2}$, respectivamente.

En contraste, los quistes de $S$. trochoidea para los cuales se ha estimado una razón de germinación de $40-50 \%$ en condiciones naturales (Wang et al. 2007), tendrán un aporte de $0.081 \times$ $10^{6}$ y $0.99 \times 10^{6}$ células germinales $\mathrm{m}^{-2}$ en SM y AG. Estas cantidades de quistes de L. polyedrum y S. trochoidea son suficientes para aportar la semilla en la columna de agua e iniciar un nuevo florecimiento por lo menos en la franja costera de la BTS.

Los análisis MDE y ANOSIM confirman que hubo tres grupos de ambientes sedimentarios asociados con las abundancias de quistes de reposo. Este arreglo está claramente asociado con el tamaño de los sedimentos descritos para la BTS (Emery et al. 1957, Barrera-Gaona 1998); es decir, las arenas gruesas a finas con $\varnothing=1$ a 3 en SM, arena fina a limos gruesos con $\varnothing=4$ a 5 en RB y una fracción de fango con $\varnothing=5$ a 6 en PI y AG.

La homogeneidad de varianza entre los grupos RB, PI y AG, junto con la heterocedasticidad encontrada en SM, confirma que las abundancias de quistes de reposo estuvieron fuertemente controladas por factores físicos. Esto sugiere que existe una clasificación por tamaños de las partículas orgánicas de acuerdo con el ambiente sedimentario de la BTS como lo ha discutido Walton (1955).

\section{Agradecimientos}

Se agradece el financiero de la Coordinación Sectorial de Desarrollo Académico (COSDAC) y la Dirección General de Educación en Ciencia y Tecnología del Mar (DGECyTM) a través del proyecto 910.06-P. El primer autor obtuvo un beca de CONACYT y SEMARNAT (2004-COI-62). Se agradece a P Chagoya-Loli, L Lafarga-Cosio y M Ortega (CETMAREnsenada), y a V Acosta-Chamorro (SEMAR) y Z MijangosAlquisires (DGECyTM) por su ayuda en el trabajo de campo y laboratorio. Dos revisores anónimos y H Maske mejoraron la versión final de este trabajo. Gracias a JM Domínguez y F Ponce por las figuras. 
Espinosa-Carreón TL, Gaxiola-Castro G, Robles-Pacheco JM, NájeraMartínez S. 2001. Temperature, salinity, nutrients and chlorophyll $a$ in coastal waters of the Southern California Bight. Cienc. Mar. 27: $397-422$.

Figueroa RI, Bravo I. 2005. Sexual reproduction and two different encystment strategies of Lingulodinium polyedrum (Dinophyceae) in culture. J. Phycol. 41: 370-379.

García-Córdova J, López MM, Pineda J, Pérez BP. 2005. Hidrografía de la costa oeste de California y Baja California. Reporte Técnico del crucero NOHYPE-1. R/V Gordon Sproul. Mayo 10-23 de 2001. Comunicaciones Académicas, Serie de Oceanografía Física, CICESE, Ensenada, BC. 37 pp.

Godhe A, Norén F, Kuylenstierna M, Ekbergi C, Karlson B. 2001. Relationship between planktonic dinoflagellate abundance, cysts recovered in sediment traps and environmental factors in the Gullmar Fjord, Sweden. J. Plankton Res. 23: 923-938.

Gregorio ED, Pieper RE. 2000. Investigations of red tides along the Southern California Coast. Bull. South. Calif. Acad. Sci. 99: 147-160.

Heiskanen AS. 1993. Mass encystment and sinking of dinoflagellates during a spring bloom. Mar. Biol. 116: 161-167.

Holmes RW, Williams PM, Eppley RW. 1967. Red water in La Jolla Bay, 1964-1966. Limnol. Oceanogr. 12: 503-512.

Holzwarth U, Esper O, Zonneveld K. 2007. Distribution of organicwalled dinoflagellate cysts in shelf surface sediments of the Benguela upwelling system in relationship to environmental conditions. Mar. Micropaleontol. 64: 91-119.

Hoorn C. 1997. Palynology of the Pleistocene glacial/interglacial cycles of the Amazon fan (Holes 940A, 944A and 946A). In: Flood RD, Piper DJW, Klaus A, Peterson LC (eds.), The Pleistocene sediments are Covered by Holocene Section. Proc. Ocean Drilling Project, Sci. Results, 155, College Station, Texas, pp. 397-409.

Ishikawa A, Taniguchi A. 1996. Contribution of benthic cysts to the population dynamics of Scrippsiella spp. (Dinophyceae) in Onagawa Bay, northeast Japan. Mar. Ecol. Prog. Ser. 140: 169-178.

Joyce LB, Pitcher GC. 2004. Encystment of Zigabikodinium lenticulatum (Dinophyceae) during a summer bloom of dinoflagellates in southern Benguela upwelling system. Estuar. Coast. Shelf Sci. 59: 1-11.

Karydis M, Ignatiades L, Moschopoulum N. 1983. An index associated with nutrient eutrophication in the marine environment. Estuar. Coast. Shelf Sci. 16: 339-344.

Lewis J, Harris A, Jones K, Edmonds R. 1999. Long-term survival of marine planktonic diatoms and dinoflagellates in stored sediment samples. J. Plankton Res. 21: 343-354.

Martínez-Hernández E, Hernández-Campos HE. 1991. Distribución de quistes de dinoflagelados y acritarcas en sedimentos holocénicos del Golfo de California. Paleontol. Mex. 57: 1-133.

Martínez-López A, Ulloa-Pérez AE, Escobedo-Urias DC. 2007. First record of vegetative cells of Pyrodinium bahamense (Gonyaulacales: Goniodomataceae) in the Gulf of California. Pac. Sci. 61: 289-293.

Montresor M, Montesarchio E, Marino D, Zingone A. 1994. Calcareous dinoflagellate cysts in marine sediments of the Gulf of Naples (Mediterranean Sea). Rev. Palaeobot. Palynol. 84: 45-56.

Mudie PJ, Rochon A, Levac E. 2002. Palynological records of red tide-producing species in Canada: Past trends and implications for the future. Palaeogeogr., Palaeoclimatol., Palaeoecol. 180: 159-186.

Nehring S. 1993. Mechanisms for recurrent nuisance algal blooms in coastal zones: Resting cyst formation as life-strategy of dinoflagellates. In: Sterr H, Hofstade J, Plag HP (eds.),
Interdisciplinary Discussion of Coastal Research and Coastal Management Issues and Problems. Proc. Int. Coastal Congress, Frankfurt, pp. 454-467.

Peña-Manjarrez JL, Gaxiola-Castro G, Helenes-Escamilla J, OrellanaCepeda E. 2001. Cysts of Lingulodinium polyedrum, red tide producing organism in Todos Santos Bay (winter-spring 2000). Cienc. Mar. 27: 543-558.

Peña-Manjarrez JL, Helenes-Escamilla J, Gaxiola-Castro G, OrellanaCepeda E. 2005. Dinoflagellate cysts and bloom events at Todos Santos Bay. Cont. Shelf Res. 25: 1375-1393.

Persson A, Rosenberg R. 2003. Impact of grazing and bioturbation of marine benthic deposit feeders on dinoflagellate cysts. Harmful Algae 2: 43-50.

Pospelova V, Pedersen TF, de Vernal A. 2006. Dinoflagellate cysts as indicators of climatic and oceanographic changes during the past $40 \mathrm{kyr}$ in the Santa Barbara Basin, southern California. Paleoceanography 21: 1-16.

Pospelova V, de Vernal A, Pedersen TF. 2008. Distribution of dinoflagellate cysts in surface sediments from the northeastern Pacific Ocean $\left(43-25^{\circ} \mathrm{N}\right)$ in relation to sea-surface temperature, salinity, productivity and coastal upwelling. Mar. Micropaleontol. 68: $21-48$.

Prauss ML. 2002. Recent global warming and its influence on marine palynology within the central Santa Barbara Basin, offshore Southern California, USA. Palynology 26: 217-238.

Radi T, DeVernal A. 2004. Dinocyst distribution in surface sediments from the nothesatern Pacific margin $\left(40-60^{\circ} \mathrm{N}\right)$ in relation to hydrographic conditions, productivity and upwelling. Rev. Paleobot. Palinol. 28: 169-193.

Reyes-Coca S, Troncoso-Gaytán R. 2004. Multidecadal variation of winter rainfall in northwestern Baja California. Cienc. Mar. 30: 99-108.

Segovia-Zavala JA, Rivera-Duarte I, Del Valle-Villorín FJ. 1988. Efectos de desechos orgánicos en las zonas adyacentes a los efluentes en Bahía de Todos Santos: Nutrientes. Cienc. Mar. 14: 81-94.

Segovia-Zavala JA, Delgadillo-Hinojosa F, Muñoz-Barbosa A, Huerta-Díaz MA, Gutiérrez-Galindo EA, Canino-Herrera R, Hernández-Ayón JM. 2007. Variabilidad espacial y balance de fosfatos sobre la plataforma continental de la región fronteriza occidental México-EUA. Cienc. Mar. 33: 229-245.

Torres CR, Mejía A, Argote ML, Ramírez I, Mancillas M. 2006. Three-dimensional circulation in Todos Santos Bay, Ensenada, BC, Mexico. In: Gámez B, Ojeda D, Larrazabal G, Cerrolaza M. (eds.), Simulación y Modelado en Ingenieria y Ciencias. SVMNI, pp. MF115-MF122.

Utermöhl H. 1958. Zur vervollkommung der quantitativen phytoplankton-methodik. Verh. Int. Ver. Limnol. 9: 1-38.

Vásquez-Bedoya LF, Radi T, Ruiz-Fernández AC, de Vernal A, Machain-Castillo ML, Kielt JF, Hillaire-Marcel C. 2008. Organicwalled dinoflagellate cysts and benthic foraminifera in coastal sediments of the last century from the Gulf of Tehuantepec, South Pacific Coast of Mexico. Mar. Micropaleontol. 68: 49-65.

Walton RW. 1955. Ecology of living benthonic foraminifera, Todos Santos Bay, BC. J. Paleontol. 26: 952-1018.

Wang ZH, Yu-Zao Q, Chen Y. 2006. Phytoplankton abundance, community structure and nutrients in cultural areas of Daya Bay, South China Sea. J. Mar. Syst. 62: 85-94.

Wang ZH, Yu-Zao Q, Yu-Feng Y. 2007. Cyst formation: An important mechanism for the termination of Scrippsiella trochoidea (Dinophyceae) bloom. J. Plankton Res. 29: 209-218.

Recibido en febrero de 2008; aceptado en noviembre de 2008. 